UDC $94 \ll 04 / 14 »$

Submitted: 31.07.2018

LBC 63.3(0)4-93

Accepted: 26.09 .2018

\title{
CHARON IN EPITAPHS OF JOHN GEOMETRES (KYRIOTES)
}

\author{
Evgeniy V. Stelnik \\ Volgograd State University, Volgograd, Russian Federation
}

\begin{abstract}
Introduction. The poetic system of the images of John Geometres has a traditional antique origin, but surprisingly the characters of Geometres' Hades and Charon acquire not an antiquarian, literary but a folkloric character. Methods. The epigrams of the Geometres (Kyriotes) are considered from the point of view of the critical approaches of hermeneutics, as they are formulated by H.-G. Gadamer. In addition, the relationship between Byzantine literature and Byzantine folklore is presented by the author in the categories of psychoanalysis.

Analysis. Based on two epitaphs of the Byzantine poet of the $10^{\text {th }}$ century John Geometres (Kyriotes), it is possible to trace the Byzantine deformation of the ancient literary images of the afterlife. This deformation occurs under pressure, by various ways of poetic tradition, of Byzantine folklore. The resultant poetic images have an original, surrogate character.

Conclusions. Byzantine rhetoricians, John Geometres (Kyriotes) among them, faced with folk ideas about Charos, comprehended them in classical categories. As a result, it was a compromise variant, combining the chthonic power of Charos and the literary tradition of Charon. This deformation takes place under pressure, which in various ways penetrates into the poetic tradition of Byzantine folklore. The resulting poetic images have an original, surrogate character. Byzantine poetry, based on the free play of metaphors and language associations, in contact with the live folk speech, have made it possible to penetrate the folklore ideas of Charos in the "closed" rhetorical genre of Byzantine literature.

Key words: Charon, Charos, Hades, John Geometres (Kyriotes), epitaph, tradition, folklore, deformation of poetic images.

Citation. Stelnik E.V. Charon in Epitaphs of John Geometres (Kyriotes). Vestnik Volgogradskogo gosudarstvennogo universiteta. Seriya 4, Istoriya. Regionovedenie. Mezhdunarodnye otnosheniya [Science Journal of Volgograd State University. History. Area Studies. International Relations], 2018, vol. 23, no. 5, pp. 179-185. (in Russian). DOI: https://doi.org/10.15688/jvolsu4.2018.5.16
\end{abstract}

УДК 94«04/14»

ББК 63.3(0)4-93
Дата поступления статьи: 31.07.2018

Дата принятия статьи: 26.09.2018

\section{ХАРОН В ЭПИТАФИЯХ ИОАННА ГЕОМЕТРА (КИРИОТА)}

\author{
Евгений Викторович Стельник \\ Волгоградский государственный университет, г. Волгоград, Российская Федерация
}

\begin{abstract}
Аннотация. Эпиграммы Иоанна Геометра (Кириота) (X в.) фиксируют интересный процесс проникновения в поэтический текст под видом стереотипных классических античных образов вытесненных фольклорных представлений. Особенно ярко деформация фольклором классических образов просматривается на примере античного Харона-лодочника. Влияние «народной» традиции (в виде очень популярных в X-XII вв. песен апелатов и акритов) превращало литературно-мифологического Харона в суррогатный образ, который продолжал сохранять традиционное античное имя (ó Xóp $\omega v)$, но приобретал характерные фольклорные ф. смыслы и выполнял функции средневекового Хароса (ó Хó́pos). Эта деформация происходит под давлением различными путями проникающего в поэтическую традицию византийского фольклора. Получившиеся в итоге поэтические образы имеют оригинальный, синтетический характер. Византийская поэзия, основывав贫 шаяся на свободной «игре» языковых ассоциаций и метафор, соприкасавшаяся со спонтанной народной કै речью, делала возможным возвращение «вытесненного» фольклорного мировоззрения и Хароса, как его () ключевого элемента, в «закрытый», элитарный жанр византийской литературы.
\end{abstract}


Ключевые слова: Харон, Харос, Аид, Иоанн Геометр (Кириот), эпитафия, традиция, фольклор, деформация поэтических образов.

Цитирование. Стельник Е. В. Харон в эпитафиях Иоанна Геометра (Кириота) // Вестник Волгоградского государственного университета. Серия 4, История. Регионоведение. Международные отношения. - 2018. T. 23, № 5. - C. 179-185. - DOI: https://doi.org/10.15688/jvolsu4.2018.5.16

Введение. Поэтическая система образов Иоанна Геометра имеет традиционное античное происхождение, но, что неожиданно, персонаж Харона у Геометра приобретает не антикварно-литературный, а фольклорный характер.

Методы. Эпиграммы Иоанна Геометра (Кириота) рассматриваются с точки зрения критических подходов герменевтики, как они сформулированы Х.-Г. Гадамером. Кроме этого, отношения между византийской литературой и византийским фольклором представлены автором в категориях психоанализа.

Анализ. Иоанн Геометр (Кириот) (935/940 - ок. 1000 г.), «отец» «политической» поэзии, является незаслуженно мало оцененным, но интереснейшим византийским поэтом. Родившись в знатной константинопольской семье, Иоанн получил элитарное риторическое и философское образование. В византийской интеллектуальной среде он по праву почитался как самый эрудированный ритор своего поколения. Иоанн Геометр - автор многочисленных риторических сочинений, а вершиной его теоретического литературного труда считается фундаментальный свод риторических уп-

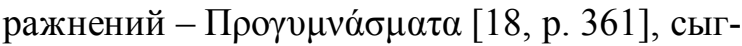
равший важную роль в литературной жизни образованного слоя Византийской империи.

Литературное признание (вместе с завистью конкурентов, которая будет сопровождать всю его жизнь) к Иоанну Геометру пришло уже в 959 г., когда автору было, видимо, всего 18 лет. В своих ранних эпиграммах Иоанн Геометр сразу обозначил славу как главную цель своей жизни. Приобрести ее он намеревался двумя путями: упражняясь в риторической эрудиции (бофі́ $)$ и совершая подвиги

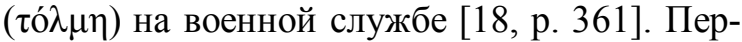
вую и большую часть своей жизни он посвятил армии.

В 985 г. жизнь императорского двора кардинально меняется. Еще недавно всесильный евнух Василий Ноф, обвиненный в попытке отравления Василия II, отправился в ссылку и вскоре погиб, а Василий II стал единоличным правителем империи. Драматически изменяется и жизнь Иоанна Геометра: аристократ, принадлежавший к проигравшей в политической борьбе фракции, тоже попадает в опалу, ему приходится уйти со службы, он теряет чин протоспафария и отправляется в монастырь Кироса [отсюда его второе имя

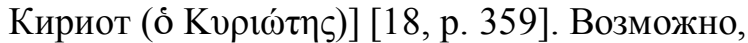
в это время ему было чуть более 50 лет.

Стихи, написанные Иоанном Геометром после 986 г., проникнуты пессимизмом и отчаяньем. Армия, как дело всей жизни Иоанна, оказалась в руках «необразованных и неопытных выскочек», которые уступают «варварам» один за другим римские города [18, p. 368-369]. Всю свою нерастраченную энергию (умноженную обидой на императора) и способности Иоанн вынужден был теперь реализовывать в литературном творчестве, которое в итоге принесло ему славу и признание.

Иоанн Геометр - автор многочисленных догматических христианских сочинений: «Энкомия на Григория Назианзина», «Комментариев на три гомилии Григория Назианзина», «Пяти гимнов о Святой Богородице», «Схолии на Евангелие от Луки» и многих других. Сомневаться в теологической компетентности Иоанна Геометра нет никаких оснований, но тем не менее «политическая» поэзия Иоанна Геометра и особенно его эпиграммы далеки от официальной религиозности. И хотя автор уже в молодости был уверен, что истина может быть найдена только в православной вере (а не в языческой философии), «застывшие» законы второй риторики в его руках создавали парадоксальную форму выражения христианского мирочувствования.

Вполне закономерно, что поэтическая система образов Иоанна Геометра имеет традиционно античное происхождение, но, что действительно неожиданно, это то, что персонаж Харона имеет не литературно-мифологический, а четко выраженный фольклорный характер. Эпиграммы Иоанна Геометра (Ки- 
риота) отмечают интересный процесс проникновения в поэтический текст под видом стереотипных классических античных образов, вытесненных «высокой» культурой фольклорных представлений. Особенно ярко деформация фольклором классических образов просматривается на примере античного Хароналодочника. Влияние «народной» традиции (в виде очень популярных в X-XII вв. песен апелатов и акритов) превращало античного Харона у Иоанна Геометра в суррогатный персонаж, который все еще сохранял традицион-

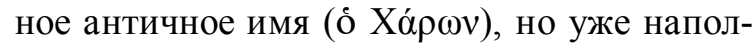
нялся существенными фольклорными смыс-

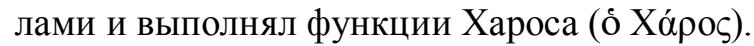

Такой синтез литературной традиции и фольклора может восприниматься исследователями как естественное для Византии слияние христианства и эллинизма [12, р. 376], как оригинальное свойство византийского энциклопедизма Х в. [4, с. 286], специфический эффект риторической техники, ищущей в массовых представлениях самые эффектные образы [19, р. 204-205]. Но, на наш взгляд, мы имеем дело с традиционным античным жанром эпиграмм [17, р. 224], в котором литературный топос «жадности» Аида у византийского автора вытесняется популярным фольклорным сюжетом «зависти» Хароса. А так как подобную трансформацию образа Харона можно наблюдать у Феодосия Диакона (поэма «Взятие Крита») [24, line 676], у Михаила Пселла [поэма на смерть севасты Марии

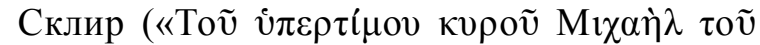

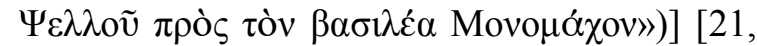
line 20] и у Евстафия Солунского (поэма «Падение Солуни») [15, р. 7], то можно говорить об универсальном процессе «ослабления» риторики и проникновения в нее элементов народной культуры.

Образ Харона у Иоанна Геометра (Кириота) описывается в двух эпиграммах. В первый раз - в епитимвии на уход из жизни патриарха Полиевкта [11, р. 313-314]. Во второй раз - в эпиграмме на похороны императрицы Елены (супруга Константина VII, которая умерла в 961 г., или, возможно, речь идет о супруге Константина VIII, которая скончалась в 980 г.) [11, p. 327].

В эпиграмме на смерть патриарха Полиевкта Харон описывается поэтом как «в

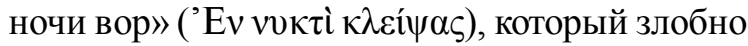
торжествует вместе с Мойрами, что завладел телом патриарха [11, р. 313], но торжествует он зря, ведь душа Полиевкта ему не досталась, а перешла к Богу. Теперь патри-

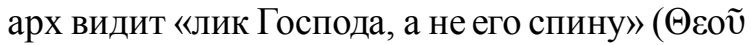

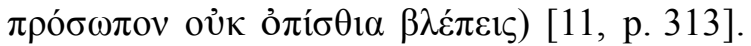
Харон у Иоанна Геометра (Кириота) - вор

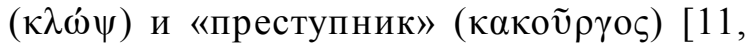
p. 314], который «ворует» ночью души людей. Надеяться на спасение так же бессмысленно, как после вора искать что-то ценное ( $\dot{\varepsilon} \varphi \omega \rho \alpha ́ \theta \eta \varsigma) ~[11$, p. 314].

Смерть, похищающая людей - это популярная тема в древнегреческой литературе, отталкивающаяся от сюжета воровства Аидом Персефоны, игравшей с подругами на цветочному лугу Нисийской равнины [2, с. 81]. Так, Палатинская антология содержит целую серию эпиграмм, в которых ворует Аид. «Ненасытный» Аид похищает младенцев [14, p. 145], детей [13, p. 366], невест [13, р. 276, $307,410]$ и любимых [13, p. 365]. Аид оказывается очень «завистлив» к человеческому счастью. Воровство Аида - традиционный топос в этом жанре античной литературы $[17$, p. 224]. Популярность и естественность этого топоса фиксирует византийский словарь «Суда» (X в.), когда определяет грабеж

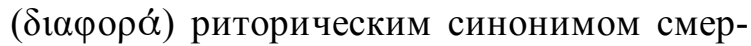
ти [23, delta 826].

Этот поэтический топос еще и морализаторская концепция. Смерть в таком контексте оказывается «незаконна», словно воровство, такая смерть преступна по своей сути. Жизнь в этом смысле является абсолютной ценностью (как и собственность), а смерти, по существу, нет, есть только «преступный произвол» и нарушение «естественного» закона жизни. Смерть в таком понимании - это всегда драма несправедливости.

Стоит обратить внимание, что в античной литературной традиции «похищает» людей только бог загробного мира Аид; старец Харон, который лишь перевозил души на своей барке по топям загробного мира, такой хтонической силой никогда не обладал.

В эпиграмме на смерть патриарха Полиевкта Харон у Иоанна Геометра (Кириота) превращается в средневекового синтетического персонажа, далекого от античной лите- 
ратурной традиции. Деформация античного образа Харона в этой эпиграмме византийского поэта привлекла интерес М. Алексиу. На ее взгляд, это самое раннее упоминание в византийской литературе нового, средневекового образа Смерти [9, р. 223]. Для сравнения, Д. Моравчик относил первое описание византийского Хароса только к ХІІІ в. [20, p. 47 68]. Показательно, что А.П. Каждан усматривал в сюжете воровства Хароном тела патриарха «святотатство» Иоанна Геометра [4, c. 282]. В Хароне А.П. Каждан видел исключительно языческого персонажа античной книжной мифологии, «чужого» для православного мировоззрения. Но, на наш взгляд, образ Харона в епитимвии Иоанна Геометра на смерть патриарха Полиевкта является ярким примером сложного, синтетического характера византийской религиозности [1, с. 154-161].

Говоря о Хароне, Иоанн Геометр, по нашему мнению, имеет в виду фольклорного Хароса, который в греческих народных песнях IX-XII вв. властвовал в «нижнем» мире и мог представляться как очень хитрый и очень находчивый вор [7, б. 64]. В «народных» представлениях Харос - это безжалостный бандит, который всю ночь ищет себе жертву, чтобы ранним утром ее ограбить и забрать жизнь. Иногда в песнях говорится, что Харос приезжает на черной лошади за своими жертвами на закате, чтобы их родные плакали на рассвете [22, p. 303].

Фольклорный Харос - это «первый вор»

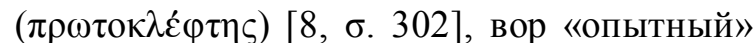
$[8, \sigma .302]$, «изворотливый» $[8$, б. 302], «жестокий» [3, с. 156] и «подлый» [8, б. 302-303]. Харос умело «читает» все «воровские сле-

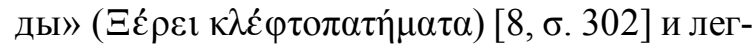
ко раскрывает даже женские уловки и хитрости $[8, \sigma .302]$. Иногда Харос - это нечестный и очень коварный торговец ( p. 304] или пират, захватывающий своих жертв в заложники и требующий выкупа у родственников [10, p. 178].

Важно обратить внимание, что в византийском фольклоре (в отличие от риторики) воровство совсем не считается пороком, а является своеобразным синонимом лихости и ловкости. Так, в греческих песнях клефты (к $\lambda \varepsilon \dot{\varphi} \tau \varepsilon \varsigma)$ гармонично воспринимаются одновременно как народные герои и искусные воры
[6, с. 84]. Смелые герои («трое храбрецов») могут даже обворовать самого Хароса, украв

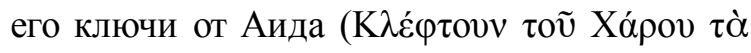

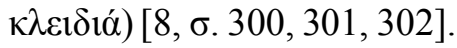

В этом фольклорном контексте Харонкак-вор в тексте Иоанна Геометра (Кириота) - это не случайный поэтический образ (неудачный, по мнению А.П. Каждана), а элемент скрытой «народной» картины мира. Воровство здесь не имеет ожидаемого нравственного аспекта, а выражает необузданную силу произвола хтонического персонажа, раскрывает архаичную модель власти потустороннего мира.

Интересно, что в библейской традиции можно найти сходное представление о воровстве как оригинальной сакральной деятельности. В Послании к фессалоникийцам указывается, что День Господень придет точно так же, как приходит вор в ночи (1 Фес. 5, 1-2). Иоанн Златоуст объясняет это место в тексте Библии в смысле неизвестности и неожиданности наступления этого ключевого для православной эсхатологии события [5, с. 497]. Само сопоставление второго Пришествия с приходом вора симптоматично.

В эпиграмме Иоанна Геометра (Кириота) на уход из жизни императрицы Елены Харон снова терпит поражение. По словам автора, теперь черная могила поглотила Елену, но недолго будет побеждать Харон ( $\dot{\alpha} \lambda \lambda^{\prime} \varepsilon i \varsigma_{\varsigma}$

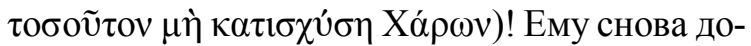
сталось только «мертвое тело», а прекрасная душа императрицы (то есть несравненно более ценное) отправилась вверх, к «духовному Солнцу» [11, p. 327]. В эпитафии Елена сравнивается с луной, которая получает свет от своего супруга-императора, который является солнцем и находится всегда выше луны. Но «духовное солнце», то есть Бог, по словам Иоанна Геометра, затмевает даже императорское сияние.

Как и в предыдущей эпиграмме, Харон вполне гармонично уживается с христианскими образами. Но христианство в этих двух эпиграммах, как, впрочем, и многих других стихах Иоанна Геометра, весьма оригинальное. Так, Д. Лаукстерманн указывал на отсутствие в тексте эпиграммы на смерть Елены даже намека на Страшный суд [11, p. 320]. Также оставляет вопросы и мотив необрати- 
мого разделения тела и души, который по своей сути является не православным, а скорее платоническим, доставшимся византийскому автору от мировоззренческих установок античных эпитафий [11, p. 320]. Христианство в этой эпиграмме заключается только в факте присутствия Бога, который не сразу, но побеждает Харона, недолго властвующего и рано радующегося. Вероятно, Харон в этом смысле сближается с образом Дьявола в патристике, чьи победы всегда призрачны. Для нас же важно отметить, что под властью Харона оказывается весь Аид, и он в своем могуществе уступает только Богу.

Сила Харона в этой эпитафии Иоанна Геометра - это бесспорный элемент византийского фольклорного мировоззрения. Показательно, что такое же значение Харон имеет и в эпитафии Георгия Акрополита (ок. 1217-1282 гг.) на смерть императора Дуки Ватаца [16, line 14 15], что, по нашему мнению, говорит о системном характере проникновения фольклорных сюжетов и в этот традиционный жанр.

Выводы. Там, где изощренная византийская литература вступала во взаимодействие со стихией живого народного языка, даже в элитарную риторику мог проникать фольклорный образ Хароса, вытесняя литературного Харона. Там, где был возможен, в силу жанровой специфики, свободный от аттических архаизмов повседневный язык, был возможен и пласт бытовых представлений.

Какими бы византийские литераторы ни были утонченными знатоками древнегреческой литературы, им все равно приходилось спускаться с интеллектуальных вершин в тривиальную повседневную жизнь. Как бы их не защищали стены классной комнаты или привилегии императорского дворца, но энергия фольклорной культуры неизбежно захватывала и их. Риторы, неизбежно сталкиваясь с фольклорными представлениями о Харосе, переосмысливали их в знакомых традиционных античных категориях. В результате получался суррогатный вариант, сочетающий хтоническую силу фольклорного Хароса и литературность античного Харона. Ключевую роль в этом процессе деформации традиционных античных образов играла византийская поэзия и, в частности, эпиграммы Иоанна Геометра (Кириота).

\section{СПИСОК ЛИТЕРАТУРЫ}

1. Барабанов, Н. Д. Проблема народной религиозности в современной историографии: уроки медиевистики / Н. Д. Барабанов // Вестник Волгоградского государственного университета. Серия 4, История. Регионоведение. Международные отношения. - 2005. - Вып. 10. - С. 154-161.

2. Гимн к Деметре // Эллинские поэты / пер. В. Вересаева. - М. : Гослитиздат, 1963. -408 с.

3. Греческие народные песни / выбрал и пер. В. Нейштадт. - М. : Гос. изд-во худож. лит., 1957. 294 c.

4. Каждан, А. П. История византийской литературы (850-1000 гг.). Эпоха энциклопедизма / А. П. Каждан. -СПб. : Алетейя, 2012.-376 с.

5. Священное писание в толкованиях святителя Иоанна Златоуста : в 10 т. - М. : Ковчег, 2006. T. 9. $-912 \mathrm{c}$.

6. Цивьян, Т. В. Лингвистические основы балканской модели мира / Т. В. Цивьян. - М. : Наука, 1990. $-210 \mathrm{c}$.

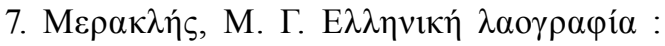

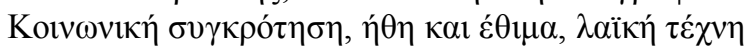

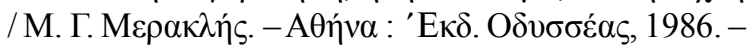
$208 \sigma$.

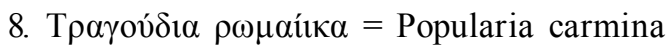
Graeciae recentioris / Ed. A. Passow. - Lipsiae : B.G. Teubner, 1860. $-650 \sigma$.

9. Alexiou, M. Modern Greek Folklore and its Relation to the Past. The Evolution of Charos in Greek Tradition / M. Alexiou // The "Past" in Medieval and Modern Greek Culture / Ed. S. Vryonis. - Malibu : Undena Publications, 1978. - P. 221-236.

10. Alexiou, M. The Ritual Lament in Greek Tradition / M. Alexiou. - Oxford : Rowman \& Littlefield Publishers, 2002. - 316 p.

11. Appendix ad excerpta poetica : Codex 352 suppl. // Anecdota graeca e codd. manuscriptis Bibliothecae regiae parisienses : in 4 vols. / ed. J. A. Cramer. - Oxford : E Typographeo academico, 1841. - Vol. 4. -452 p.

12. De Groote, M. Joannes Geometres. Metaphrasis of the Odes : Critical Edition / M. de Groote // Greek, Roman, and Byzantine Studies. - 2004. Vol. 44. - P. 375-410.

13. Epigrammatum Anthologia Palatina cum Planudeis et appendice nova epigrammatum veterum ex libris et marmoribus ductorum. Vol. 1 : Cap. I-VIII / Instr. F. Dübner. - Parisiis : Ambrosio Firmin Didot, 1864. $-572 \mathrm{p}$.

14. Epigrammatum Anthologia Palatina cum Planudeis et appendice nova epigrammatum veterum ex libris et marmoribus ductorum. Vol. 3 : Appendix nova / instr. E. Cougny. - Paris : Ambrosio Firmin Didot, 1890. $-631 \mathrm{p}$. 
15. Eustathios of the Thessaloniki. Capture of Thessaloniki / transl. J. R. Melville Jones. Canberra: The Australian National University, 1998. $-246 \mathrm{p}$.

16. Georgii Acropolitae. Epitaphius in Joannem Ducam/Georgii Acropolitae// Georgii Acropolitae opera : in 2 vols. Vol. 2. Continens Scripta minora, praecedit dissertatio de vita scriptoris / ed. A. Heisenberg. Stuttgart : Teubner, 1978. - $120 \mathrm{p}$.

17. Lauxtermann, M. D. Byzantine Poetry from Pisides to Geometers : Texts and Contexts. Vol. 1 / M. D. Lauxtermann. - Wien : Verl. d. Österr. Akad. d. Wiss., 2003. -390 p.

18. Lauxtermann, M. D. John Geometres - Poet and Soldier / M. D. Lauxtermann // Byzantion. - 1998. T. 68, Fasc. 2. - P. 356-380.

19. Mihálykó, Á. T. Christ and Charon : PGMP13 reconsidered / Á. T. Mihálykó // Symbolae Osloenses. - 2015. - № 89. - P. 183-209.

20. Moravesik, G. Il Caronte Bizantino / G. Moravcsik // Studi Bizantini o Neoellenici. - 1931. № 3. - P. 45-68.

21. Psellus Michael. Poemata/Ed. L. G. Westerink. Stuttgart; Leipzig : B. G. Teubner, 1992. - 550 S

22. Saunier, G. Charos et l'Histoire dans les chansons populaires grecques / G. Saunier // Revue des études grecques. - 1982. - Vol. 95, № 452. - P. 297-321.

23. Suidae Lexicon : 5 Bd. Bd. 1 / Ed. A. Adler. Lipsiae : B.G. Teubneri, 1928. - 549 p. ; Bd. 2 / Ed. A. Adler.-Lipsiae: B.G. Teubneri, 1931.-740 p. ; Bd. 3 / Ed. A. Adler. - Lipsiae : B.G. Teubneri, 1933.632 p. ; Bd. 4 / Ed. A. Adler. - Lipsiae : B.G. Teubneri, 1935. - 854 p. ; Bd. 5 / Ed. A. Adler. - Lipsiae : B.G. Teubneri, 1938. $-280 \mathrm{p}$.

24. Theodosii Diaconi. De Creta capta / Ed. H. Criscuolo. - Leipzig : Teubner, 1979. -68 p.

\section{REFERENCES}

1. Barabanov N.D. Problema narodnoy religioznosti v sovremennoy istoriografii: uroki medievistiki [The Problem of Popular Religiosity in Modern Historiography: Examples of Medieval Studies]. Vestnik Volgogradskogo gosudarstvennogo universiteta. Seriya 4, Istoriya. Regionovedenie. Mezhdunarodnye otnosheniya [Science Journal of Volgograd State University. History. Area Studies. International Relations], 2005, vol. 10, pp. 154-161 (in Russian).

2. Veresaev V., ed. Gimn k Demetre [A Hymn to Demeter]. Ellinskie poety [Hellenic poets]. Moscow, Goslitizdat Publ., 1963. 408 p. (in Russian).

3. Neushtadt V., ed. Grecheskie narodnye pesni [The Greek Popular Songs]. Moscow, Gos. izd-vo khudozh. lit. Publ., 1957. 294 p. (in Russian).
4. Kazhdan A.P. Istoriya vizantiyskoy literatury (850-1000 gg.). Epokha entsyklopedizma [History of the Byzantine Literature (850-1000). Age of Encyclopaedism]. Saint Petersburg, Aletheia Publ., 2012.376 p. (in Russian).

5. Svyashchennoe pisanie v tolkovaniyakh svyatitelya Ioanna Zlatousta: v $10 t$. [The Scripture in Interpretations of St. John Chrysostom in 10 vols.]. Moscow, Kovcheg Publ., 2006, vol. 9. 912 p. (in Russian).

6. Tsivian T.V. Lingvisticheskie osnovy balkanskoy modeli mira [Linguistic Basis of the Balkan Model of the World]. Moskow, Nauka Publ., 1990. 210 p. (in Russian).

7. Meraklēs M.G. Ellēnikē laografia: koinonikē sugkrotēsē, èthē kai ethima, laikē texnē [Greek Folklore: Social Formation, Habits and Customs, Folk Art]. Athens, Ekdoseis Odysseas Publ., 1986. 208 p. (in Greek).

8. Passow A., ed. Tragoudia rōmaiika [The Roman Songs] = Popularia carmina Graeciae recentioris. Lipsiae, B.G. Teubner, 1860. 650 p.

9. Alexiou M. Modern Greek Folklore and its Relation to the Past. The Evolution of Charos in Greek Tradition. Vryonis S., ed. The "Past" in Medieval and Modern Greek Culture. Malibu, Undena Publications, 1978, pp. 221-236.

10. Alexiou M. The Ritual Lament in Greek Tradition. Oxford, Rowman \& Littlefield Publishers, 2002.316 p.

11. Appendix ad excerpta poetica: codex 352 suppl. Cramer J.A., ed. Anecdota graeca e codd. manuscriptis Bibliothecae regiae parisienses: in 4 vols. Oxford, E Typographeo academico, 1841. Vol. 4. $452 \mathrm{p}$.

12. De Groote M. Joannes Geometres. Metaphrasis of the Odes: Critical Edition. Greek, Roman, and Byzantine Studies, 2004, vol. 44, pp. 375-410.

13. Dübner F., ed. Epigrammatum Anthologia Palatina cum Planudeis et appendice nova epigrammatum veterum ex libris et marmoribus ductorum. Vol. 1: Cap. I-VIII. Parisiis, Ambrosio Firmin Didot, 1864. 572 p.

14. Cougny E., ed. Epigrammatum Anthologia Palatina cum Planudeis et appendice nova epigrammatum veterum ex libris et marmoribus ductorum. Vol. 3: Appendix nova. Paris, Ambrosio Firmin Didot, 1890. 631 p.

15. Melville Jones J.R., ed. Eustathios of the Thessaloniki. Capture of Thessaloniki. Canberra, The Australian National University, 1998. 246 p.

16. Georgii Acropolitae. Epitaphius in Joannem Ducam. Heisenberg A., ed. Georgii Acropolitae opera: in 2 vols. Vol. 2. Continens Scripta minora, praecedit dissertatio de vita scriptoris. Stuttgart, Teubner, 1978. $120 \mathrm{p}$. 
17. Lauxtermann M.D. Byzantine Poetry from Pisides to Geometers: Texts and Contexts. Wien, Verlag der Österreichischen Akademie der Wissenschaften, 2003, vol. 1.390 p.

18. Lauxtermann M.D. John Geometres - Poet and Soldier. Byzantion, 1998, vol. 68, fasc. 2, pp. 356-380.

19. Mihálykó Á.T. Christ and Charon: PGM P13 reconsidered. Symbolae Osloenses, 2015, no. 89, pp. 183-209.

20. Moravcsik G. Il Caronte Bizantino. Studi Bizantini o Neoellenici, 1931, no. 3, pp. 45-68.
21. Westerink L.G., ed. Psellus Michael. Poemata. Stuttgart; Leipzig, B. G. Teubner, 1992. 550 p.

22. Saunier G. Charos et l'Histoire dans les chansons populaires grecques. Revue des études grecques, 1982, vol. 95, no. 452, pp. 297-321.

23. Adler A., ed. Suidae Lexicon: 5 Bd. Bd. 1. Lipsiae, B.G. Teubneri, 1928. 549 p.; Bd. 2. Lipsiae, B.G. Teubneri, 1931. 740 p.; Bd. 3. Lipsiae, B.G. Teubneri, 1933. 632 p.; Bd. 4. Lipsiae, B.G. Teubneri, 1935. 854 p.; Bd. 5. Lipsiae, B.G. Teubneri, 1938. 280 p.

24. Criscuolo H., ed. Theodosii Diaconi. De Creta capta. Leipzig, Teubner, 1979. 68 p.

\section{Information about the Author}

Evgeniy V. Stelnik, Candidate of Sciences (History), Senior Lecturer, Department of Service and Tourism, Volgograd State University, Prosp. Universitetsky, 100, 400062 Volgograd, Russian Federation, analitika@volsu.ru,https://orcid.org/0000-0003-1097-1161

\section{Информация об авторе}

Евгений Викторович Стельник, кандидат исторических наук, старший преподаватель кафедры сервиса и туризма, Волгоградский государственный университет, просп. Университетский, 100, 400062 г. Волгоград, Российская Федерация, analitika@volsu.ru, https://orcid.org/ 0000-0003-1097-1161 